\title{
Major clinical and angiographic outcome of drug eluting stents in native ostial coronary artery disease
}

\author{
Khaled R. Abd El Meguid', Hesham B. Mahmoud ${ }^{1}$, Fouad R. Amin², Jonathan R. Clague ${ }^{3}$ \\ ${ }^{1}$ Division of Cardiology, Beni-Suef University Hospital, Beni-Suef, Egypt \\ ${ }^{2}$ Division of Cardiology, Heatherwood \& Wexham Park Hospitals, London, UK \\ ${ }^{3}$ Division of Cardiology, Royal Brompton Hospital, Imperial College, London, UK \\ Email: krefaat20@hotmail.com
}

Received 5 March 2013; revised 27 April 2013; accepted 14 May 2013

Copyright (C) 2013 Khaled R. Abd El Meguid et al. This is an open access article distributed under the Creative Commons Attribution License, which permits unrestricted use, distribution, and reproduction in any medium, provided the original work is properly cited.

\begin{abstract}
Objectives: The study was designed to evaluate the efficacy and safety of drug eluting stents (DESs) in aorto-ostial (A-O) coronary artery lesions, in terms of early and late restenosis rate; including clinical assessment, non-invasive stress testing and angiographic follow-up. Also, the study was aimed to compare the results of implantation of drug eluting stents (DES) to that of bare metal stents (BMS) in aortoostial lesions done over a previous 5 years in Royal Brompton Hospital. Background: The safety and effectiveness of DESs for the treatment of aorto-ostial lesions. Methods: We included 161 consecutive patients with symptoms subjective of angina pectoris or objective evidence of myocardial ischemia; who underwent percutaneous coronary interventions (PCI) in coronary ostial lesions using DES. The patients were divided into two groups based on the site of ostial lesion. The control group consisted of 125 consecutive patients who underwent percutaneous coronary intervention for ostial lesions using bare metal stents (BMS) implantation in the period immediately before the introduction of DES. The incidence of major adverse cardiac events (MACE), including death or Q-wave myocardial infarction (MI), need for repeated revascularization procedure CABG or angioplasty, were recorded in-hospital and at twelve months \pm 3 months. Follow-up angiography was only performed in case of recurrent symptoms subjective of myocardial ischemia or if there was objective evidence of myocardial ischemia by stress testing. Results: The initial procedure was successful in 149 patients $(92.5 \%)$ in the DES arm. There were no statistically significant major in-hospital complications in the DES group, compared to BMS group which showed 4 cases of in-hospital deaths $(p=0.017)$. At Twelve months \pm 3 months follow-up, MACE were
\end{abstract}

significantly less frequent in the DES group compared to the BMS group, including death $(0.8 \%$ vs. $6.4 \%$, $p=0.004)$ and need for CABG $(1.7 \%$ vs. $10 \%, p=$ 0.012). Conclusions: The main finding of our study is that, compared to the BMS, implantation of the DES in coronary ostial lesions appears safe and effective. It is associated with high procedural success rate, low immediate and in-hospital complication rate, infrequent late adverse events and favourable long-term clinical and angiographic outcomes compared with bare metal stents implantation at 12-month follow-up. Advanced age, previous myocardial infarction and acute coronary syndromes at presentation were all found to be independent positive predictors for clinical events after drug eluting stent implantation in ostial lesions.

Keywords: Bare Metal Stent; DRUG Eluting Stent; Ostial Coronary Lesions

\section{INTRODUCTION}

Ostial coronary artery lesions constitute a distinct substrate for percutaneous intervention, as they differ from other lesion sites in management strategies and in clinical out-come. The high concentration of elastic muscle fibers around the ostium, and the presence of atherosclerosis and fibrosis of the aortic wall in case of aorto-ostial (A-O) and proximal left main coronary artery (LMCA), has been proposed as a possible mechanisms of elastic recoil and high restenosis rate in these sites [1,2]. In addition, the presence of ostial calcification contributes to further lesions rigidity [3]. Hence these lesions appear to be both rigid and elastic at the same time [4].

Percutaneous intervention for aorto-ostial (A-O) lesions have been associated with lower procedural success 
rates of $70 \%-97 \%$, more frequent in hospital complications of $5 \%-12 \%$, and greater likelihood of late restenosis of $28 \%-52 \%$ when compared with treatment of non aorta-ostial lesions [5,6]. Excimer laser coronary angioplasty had a high initial angiographic and clinical success rates but restenosis was a limitation [7].

The beneficial action of stents has been attributed to maximizing the initial luminal gain and overcoming the aorto-ostial elastic recoil [8,9]. Silvestri et al., on 2000 [10] confirmed the feasibility and safety of stent-supported angioplasty of the left main coronary artery leading to acceptable morbidity, with a 6 month target lesion revascularization (TLR) rate of $17 \%$. Stenting of ostial left anterior descending artery (LAD) lesions were associated with better event-free survival, and less target lesion revascularization (TLR) of $10.5 \%$ compared to directional atherectomy alone $50 \%$ [11].

Drug eluting stents have a potent anti-inflammatory, immunosuppressive, and anti-prolefrative effect [12,13].

Drug eluting stents (DES) have been shown to reduce the incidence of restenosis even in very complex lesions $[14,15]$, but critical aorto-ostial lesions were not included in many trails [16-18].

\section{AIM OF THE STUDY}

To evaluate the efficacy of drug eluting stents in aortoostial (A-O) coronary artery lesions, in terms of early and late restenosis rate, clinical assessment, non-invasive stress testing and angiographic follow-up.

\section{METHODS}

Study patients: Our study group included all patients with ostial lesions who underwent elective drug eluting stent (DES) deployment with either Sirolimus eluting stents (Cypher, Cordis/Johnson and Johnson) or Paclitaxel-eluting stents (Taxus, Boston Scientific) in a native ostial coronary artery. The population consisted of 161 patients divided into two groups with symptoms subjecttive of angina pectoris or objective evidence of myocardial ischemia, with suitable coronary anatomy for percutaneous revascularization. The control group consisted of 125 consecutive patients who underwent percutaneous coronary intervention for ostial lesions using bare metal stents (BMS).

Exclusion criteria:

*Target vessel reference diameter smaller than 2.5 $\mathrm{mm}$.

*Stent implantation during cardiogenic shock or as a bridge to emergency CABG.

*Contraindication to antiplatelet agents.

*Myocardial infarction within 48 hours.

*Heavy calcified ostial lesions.
An aorto-ostial lesion was defined as a $>70 \%$ stenosis located at the aortic junction with the left main coronary artery, right coronary artery within $3 \mathrm{~mm}$ of the vessel origin on the view of least foreshortened angiographic projection [19-22]. Group I: the aorto-ostial lesions include left main coronary artery (LMCA) and right coronary artery (RCA) ostial lesions. Group II: the non aorto-ostial lesions include left anterior descending coronary artery (LAD), left circumflex coronary artery (LCX), diagonal branches (D), obtuse marginal (OM), and posterior descending coronary artery (PDA).

Stenting procedures and antiplatelet medications: Details of the stenting technique have been previously described [23,24]. All patients were pre-treated with clopidogrel and aspirin. Clopidogrel (75 mg/day) was prescribed for $\geq 12$ months after DES implantation and prescribed for $\geq 3$ month after BMS implantation.

Follow-up: The primary endpoints included major adverse cardiac events MACE (death, MI, need for repeat revascularization procedure $\mathrm{CABG}$ or angioplasty). Follow-up angiography was only performed in case of recurrent symptoms subjective of myocardial ischemia or if there was objective evidence of myocardial ischemia by stress testing.

\section{RESULTS}

Baseline patient and lesion characteristics: The clinical and lesion characteristics were similar between the DES group and the BMS group, except for the higher incidence of hypertension, hypercholesterolemia and patient clinical presentation (CCS III/IV functional class) in the DES group $74.4 \%$ vs. $37.6 \% \mathrm{p}<0.001,79.8 \%$ vs. $64 \%$ p 0.003 and $69.6 \%$ vs. $37.6 \%$ p $<0.001$ respectively. However, patients in the BMS group had higher number of smokers and previous CABG in proportion to the DES group $53.6 \%$ vs. $16.1 \mathrm{p}<0.001$ and $41.6 \%$ vs. $20.5 \%$ p $<$ 0.001 respectively (Table 1 ).

Table 1. Combined comparison between DES and BMS.

\begin{tabular}{cccc}
\hline & Total DES & Total BMS & p Value \\
\hline Age & $65( \pm 11.6)$ & $66( \pm 8)$ & 0.39 \\
Male & $126(75.0)$ & $99(79 \%)$ & 0.4 \\
Smoker & $27(16.1)$ & $67(53.6 \%)$ & $<0.001$ \\
HT & $125(74.4)$ & $47(37.6 \%)$ & $<0.001$ \\
DM & $47(28.1)$ & $26(20.8 \%)$ & 0.152 \\
HCL & $134(79.8)$ & $80(64 \%)$ & 0.003 \\
\hline Family History & $84(50.3)$ & $53(42.4 \%)$ & 0.181 \\
Previous MI & $82(48.8)$ & $66(52.8 \%)$ & 0.499 \\
Previous CABG & $35(20.5)$ & $52(41.6 \%)$ & $<0.001$ \\
CCS III \& IV & $117(69.6)$ & $47(37.6 \%)$ & $<0.001$ \\
\hline EF < 50\% & $29(19.5)$ & $35(28 \%)$ & 0.172 \\
\hline
\end{tabular}


Procedural success and in-hospital complications: There was no statistically significant difference in terms of procedural success, MI and emergency CABG between the two groups. However, there were 4 cases of in-hospital deaths in the BMS treated patients compared to no in-hospital deaths in the DES treated patients which was statistically significant with $p$ value of 0.017 . Three of the 4 deaths in the BMS treated patient during hospitalization were in the aorto-ostial lesion group with $\mathrm{p}$ value 0.001 , and 1 patient had emergency CABG from the non aorto-ostial lesion group. The total procedural success in the BMS treated group was 117 patients $93.6 \%$ vs. 163 patients $92.1 \%$ in the DES group (Table 2).

Long-term clinical outcomes: Twelve month \pm 3 month cumulative clinical follow-up was available in 155 out of 161 patients $(96.2 \%)$ in the DES treated patients, representing 41 patients $(100 \%)$ in aorto-ostial lesion group, 109 patients $(95.6 \%)$ in the non aorto-ostial group vs. 109 patients out of 125 patients $(87.2 \%)$ in the BMS treated patients, representing 41 patients $(87.2 \%)$ in the aorto-ostial lesion group and 68 patients $(80.1 \%)$ in the non aorto-ostial lesion group (Table 3).

During the follow-up period one patient in the DES treated group $(0.8 \%)$ died suddenly within two month from the date of the procedure, the patient was in the non aorto-ostial lesion group with ostial Taxus stent in an OM branch. During the same follow-up period 7 patients $(6.4 \%)$ in the BMS treated group died with a $\mathrm{p}$ value of 0.004 (Table 3). Three of the 7 patients were in the aortoostial lesion group $(7.3 \%)$ with a $p$ value of 0.003 .

During the follow-up period 4 patients in the DES treated patients $(2.3 \%)$ had MI, two patients in the non-aorto ostial lesion group (1.7\%) and 2 patients in the

Table 2. Total procedural success and in-hospital complications.

\begin{tabular}{cccc}
\hline & Total DES & Total BMS & p Value \\
\hline Procedural Success & $149(92.5 \%)$ & $117(93.6 \%)$ & 0.619 \\
Death & $0(0)$ & $4(3.6 \%)$ & 0.017 \\
MI & $3(1.7)$ & $3(2.7 \%)$ & 0.665 \\
CABG & $0(0)$ & $1(0.9 \%)$ & 0.233 \\
\hline
\end{tabular}

Table 3. Long term clinical outcomes.

\begin{tabular}{cccc}
\hline & $\begin{array}{c}\text { Total DES 155 } \\
\text { Patients (96.2\%) }\end{array}$ & $\begin{array}{c}\text { Total BMS 109 } \\
\text { Patients (87.2\%) }\end{array}$ & p Value \\
\hline Death & $1(0.8)$ & $7(6.4 \%)$ & 0.004 \\
MI & $4(2.3)$ & $2(1.8 \%)$ & 0.776 \\
CABG & $3(1.7)$ & $11(10 \%)$ & 0.012 \\
Re-PTCA & $15(8.8)$ & $13(12 \%)$ & 0.302 \\
\hline
\end{tabular}

aorto-ostial group. In the BMS treated group only 2 patients $(1.8 \%)$ had MI during the follow-up period being the 2 patients in the non aorto-ostial lesion group (4.7\%) (Table 3).

Emergency coronary artery bypass graft was performed in 3 patients $(1.7 \%)$ in the DES treated group vs. 11 patients $(10 \%)$ in BMS treated group with a $p$ value of 0.012 which was statistically significant (Table 3 ).

Long-term angiographic outcomes: During the follow-up period 69 patients $(44 \%)$ in the DES treated group (21 patients in the aorto-ostial lesion group and 48 patients in the non aorto-ostial lesion group) had a follow-up coronary angiography because of either recurrent chest pain or objective evidence of ischemia by stress testing. Binary restenosis defined as $>50 \%$ stenosis by quantitative coronary angiography (QCA) within the stented segment was documented in 20 patients $(28.9 \%)$ out of the 69 patients by coronary angiography.

Four patients in the aorto-ostial lesion group representing $10 \%$ of the original 41 patients had binary restenosis, 3 patients had complete instent restenosis (ISR) involving ostial right coronary artery (RCA) and one patient had severe ISR involving protected left main coronary artery (LMCA) including three Taxus stents and one Cypher stent. All the 4 patients had successful redo-coronary angioplasty with good results.

Twelve patients in the non aorto-ostial lesion group representing $10.4 \%$ of the original 120 patients had documented ISR during coronary angiography involving 6 patients with ostial stenting of LCX, one patient with ostial LAD stent and another one patient with ostial PDA, and two patients in each ostial diagonal and ostial obtuse marginal lesions including 5 Taxus and 7 Cypher stents. Seven patients with ISR were treated with redo-percutaneous coronary angioplasty (PTCA), 1 patient had emergency coronary artery bypass graft $(\mathrm{CABG})$, and medical treatment was recommended for 3 patients.

Figures 1-5 represent example of different patients included in the research work with different sites of ostial lesions in the Coronary tree.

The comparison of quantitative coronary angiography between DES and BMS treated patients is presented in (Table 4).

Predictors of long term clinical outcomes in DES treated patients: Combined univariate correlation between the incidences of clinical events and procedural variables in patients treated with DES is shown in Table 5. The predictors of long term clinical events include age (odds ratio $\{\mathrm{OR}\} 1.033,95 \%$ confidence interval $\{\mathrm{CI}\}$ 1.005 to 1.062 , p value 0.021 ), previous myocardial infarction (OR 2.56, 95\% CI 1.387 to 4.74, p value 0.003 ), Previous CABG (OR 4.16, 95\% CI 1.90 to 9.06 , p value 0.001 ), Taxus stent (OR $0.46,95 \%$ CI 0.25 to $0.85, \mathrm{p}$ value 0.013 ), and baseline reference vessel diameter (OR 


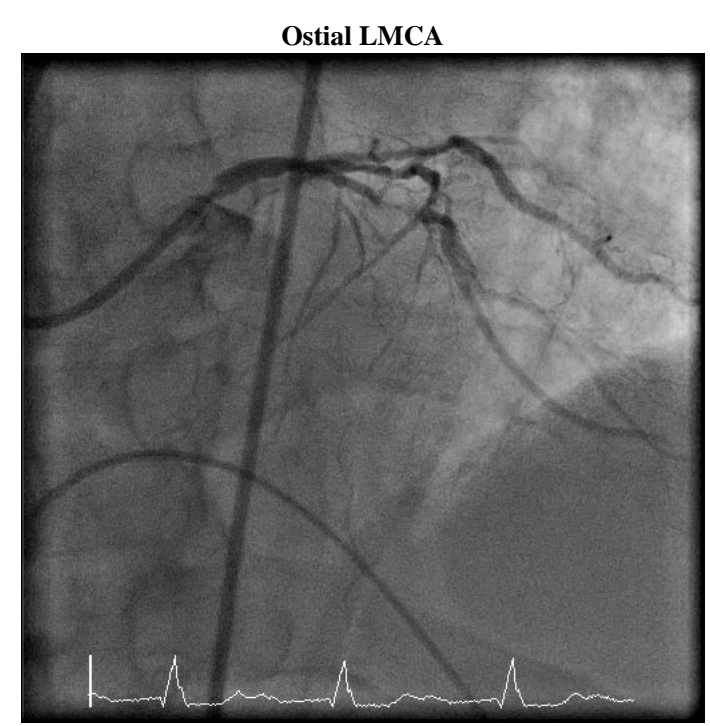

Figure 1. Base line severe ostial LMCA.

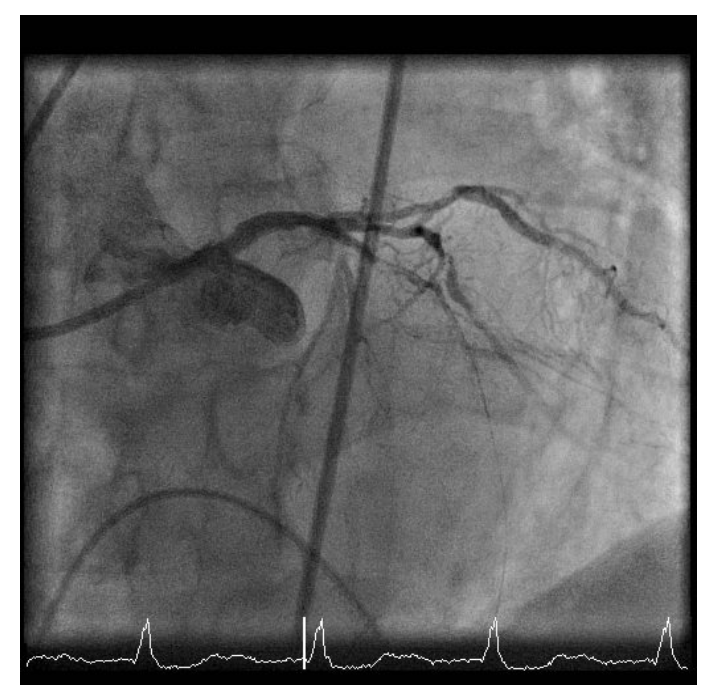

Figure 2. Taxus stent $(3.5 \times 8)$ insertion in ostial LMCA.

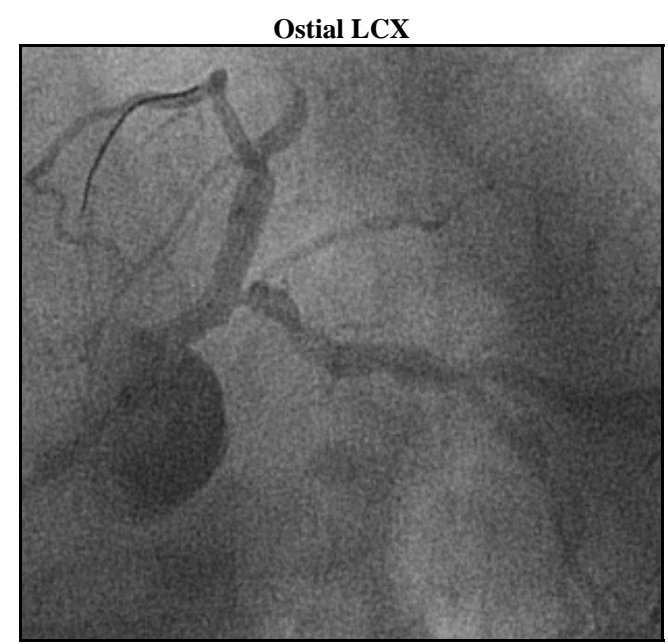

Figure 3. Base line severe ostial LCX lesion.

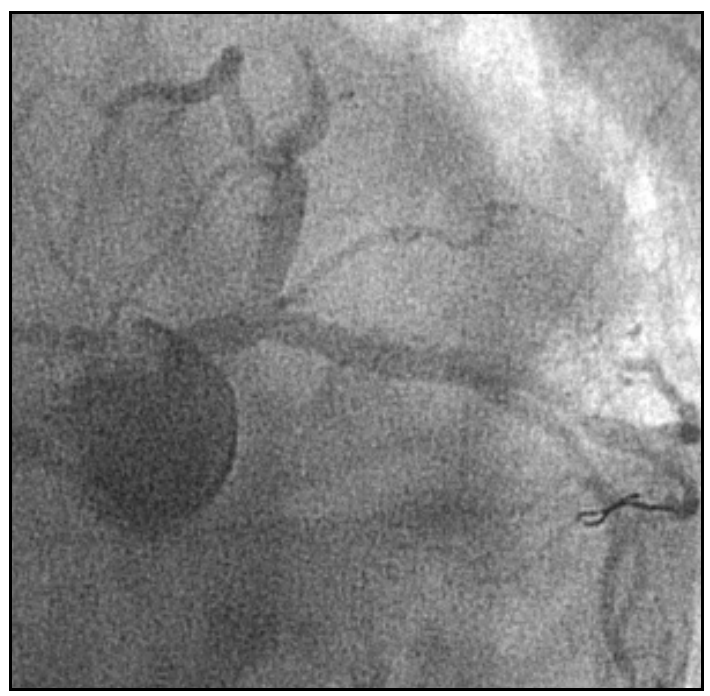

Figure 4. Cypher stent $(3.0 \times 33)$ insertion in ostial LCX.

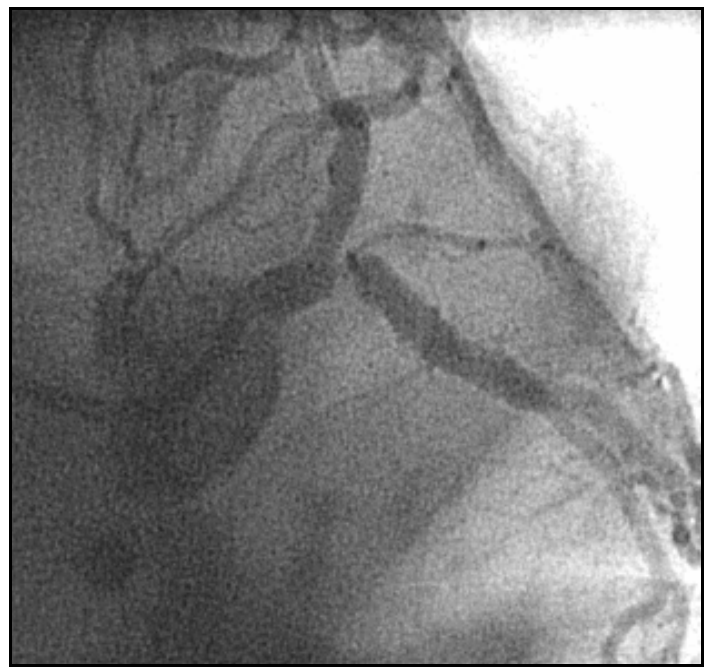

Figure 5. Follow-up angiogram done after 5.5 months showing ostial LCX in-stent restenosis.

$0.40,95 \%$ CI 0.17 to 0.91 , p value 0.03 ).

Predictors of long term angiographic outcomes in DES treated patients: In both groups there was no statistically significant correlation between any of the univariate predictors and the incidence of instent restenosis during long term follow-up period. However, in the non aorto-ostial group impaired left ventricular function in terms of ejection fraction ( $\mathrm{LV} \mathrm{EF}<50 \%$ ) was the only positive predictor of instent restenosis during the follow-up period (OR 4.71, 95\% CI 1.169 to 19.020 , p value 0.045$)$.

\section{DISCUSSION}

The main finding of our study is that implantation of DES for treatment of atherosclerotic coronary ostial lesions appears safe and effective with very high proce- 
Table 4. Quantitative angiographic parameters at baseline, end of procedure and follow-up.

\begin{tabular}{cccc}
\hline (A) & AO (DES) & AO (BMS) & p \\
\hline pre RVD $^{*}$ & $2.6( \pm 0.5)$ & $3.4( \pm 1.1)$ & 0.003 \\
pre MLD $^{* *}$ & $0.9( \pm 0.3)$ & $1.24( \pm 0.58)$ & 0.036 \\
pre \% Stenosis $^{* * *}$ & $84( \pm 10.1 \%)$ & $62( \pm 15 \%)$ & $<0.001$ \\
post MLD & $2.8( \pm 0.6)$ & $2.9( \pm 0.54)$ & 0.538 \\
Residual \% Stenosis & $23.2( \pm 9.3 \%)$ & $12.2( \pm 12.1 \%)$ & 0.002 \\
Follow-up MLD & $2.1( \pm 0.8)$ & $1.7( \pm 1.3)$ & 0.217 \\
Follow-up \% Stenosis & $42.2( \pm 24.5 \%)$ & $42.1( \pm 35 \%)$ & 0.991 \\
\hline
\end{tabular}

\begin{tabular}{cccc}
\hline (B) & Non-AO (DES) & Non-AO (BMS) & p \\
\hline pre RVD & $2.7( \pm 0.6)$ & $2.7( \pm 0.7)$ & 1 \\
pre MLD & $1( \pm 0.3)$ & $0.78( \pm 0.62)$ & 0.037 \\
pre \% Stenosis & $84.5( \pm 8.1 \%)$ & $72( \pm 19 \%)$ & $<0.001$ \\
post MLD & $2.5( \pm 0.5)$ & $2.6( \pm 0.8)$ & 0.512 \\
Residual \% Stenosis & $22.6( \pm 9.6 \%)$ & $18.8( \pm 15.2 \%)$ & 0.203 \\
Follow-up MLD & $1.9( \pm 0.6)$ & $1.9( \pm 1.2)$ & 0.816 \\
Follow-up \% Stenosis & $40( \pm 21.2 \%)$ & $35.2( \pm 33.1 \%)$ & 0.462 \\
\hline
\end{tabular}

RVD $^{*}$ : Reference vessel diameter; MLD $^{* *}$ : Minimal luminal diameter; $\%$ Stenosis ${ }^{* * *}:$ Percent stenosis.

Table 5. Combined predictors of long-term clinical outcomes (DES).

\begin{tabular}{|c|c|c|c|c|}
\hline \multirow{2}{*}{$\begin{array}{l}\text { Variable } \\
\text { Age }\end{array}$} & \multirow{2}{*}{$\begin{array}{c}\text { Odds Ratio } \\
1.033\end{array}$} & \multicolumn{2}{|c|}{$95 \%$ CI } & \multirow{2}{*}{$\begin{array}{c}\text { p value } \\
0.021\end{array}$} \\
\hline & & 1.005 & 1.062 & \\
\hline Male & 1.700 & 0.836 & 3.458 & 0.143 \\
\hline Hypertension & 1.561 & 0.764 & 3.188 & 0.222 \\
\hline Diabetes Mellitus & 1.253 & 0.652 & 2.408 & 0.498 \\
\hline Smoker & 0.540 & 0.226 & 1.289 & 0.165 \\
\hline Hypercholesterolemia & 0.903 & 0.425 & 1.918 & 0.791 \\
\hline PVD $^{*}$ & 1.813 & 0.918 & 3.583 & 0.087 \\
\hline Family History & 1.256 & 0.690 & 2.285 & 0.456 \\
\hline Impaired LV EF & 1.883 & 0.880 & 4.029 & 0.103 \\
\hline NYHA III & 1.070 & 0.713 & 1.606 & 0.744 \\
\hline CCS IV & 1.364 & 0.959 & 1.941 & 0.085 \\
\hline Previous MI $^{\#}$ & 2.566 & 1.387 & 4.746 & 0.003 \\
\hline High S. Creatinine & 0.833 & 0.363 & 1.913 & 0.667 \\
\hline ICT & 1.010 & 0.469 & 2.173 & 0.98 \\
\hline Taxus Stent & 0.462 & 0.250 & 0.852 & 0.013 \\
\hline Stent size & 0.813 & 0.372 & 1.775 & 0.603 \\
\hline Stent length & 1.030 & 0.988 & 1.073 & 0.162 \\
\hline Base line RVD & 0.400 & 0.174 & 0.915 & 0.03 \\
\hline
\end{tabular}

$\mathrm{PVD}^{*}$ : Peripheral vascular disease; Previous MI": Myocardial infarction. dural success rate $98.8 \%$, no increase in major in-hospital complications $1.7 \%$ and a significant benefit in respect to the incidence of restenosis and late event rates during long term follow-up period being $8.8 \%$ and $4.6 \%$ respectively. The findings of the current study are similar to the results of the major drug-eluting stent randomized trials, which invariably showed dramatic decrease in restenosis rates major cardiac events with the use of DES [25-27]. This study has been designed so that the results of DES implantation were compared with those of BMS implantation in coronary ostial lesions that was conducted during a different period. The rate of procedural success in the BMS treated patients was $93.6 \%$, the incidences of major in-hospital cardiac events, and long term clinical and angiographic outcomes including angiographically documented instent restenosis were higher than that of DES group. These results have been supported by previous studies [28,29].

A study done by Park et al (28) on the results of DES implantation for aorto-ostial lesions in terms of angiographic restenosis and adverse cardiac events concluded that utilization of DES to treat aorto-ostial lesions appears safe and feasible, with a very high procedural success rate $99.5 \%$; a marked benefit with respect to rates of restenosis $(60 \%$ relative risk reduction) and MACEs (51\% relative risk reduction) emerged in patients with DESs compared with those with BMSs, thus confirming the results of our study and a previous observation done on the clinical and angiographic outcomes of Sirolimus eluting stents in ostial lesions [29].

The effect of base-line reference vessel diameter on long-term clinical events after DES implantation has been documented in our study as an independent predicttor of long term clinical events in all ostial lesions (OR 0.400 , CI $95 \% 0.174$ to $0.915, \mathrm{p}$ value 0.03 ), with a greater reference to the non aorto-ostial lesion group (OR 0.245 , CI $95 \% 0.077$ to $0.776, p$ value 0.017 ). In addition to reference vessel diameter, recurrent anginal symptoms and positive objective evidence of ischemia during follow-up period were considered independent parameters on instent restenosis in the DES treated group.

Although, the performance of the 2 drug eluting stents (Cypher and Taxus) was similar in our study, the clinical follow-up data suggested a benefit of Paclitaxel eluting stents (Taxus stents) implantation as a negative predictor of long term clinical outcomes in DES treated ostial lesions (OR 0.462 , CI $95 \% 0.250$ to 0.852 , $\mathrm{p}$ value 0.013 ) which was more observed in the aorto-ostial group (OR 0.194 , CI $95 \% 0.048$ to 0.782 , $\mathrm{p}$ value 0.021 ). Although, these findings are in concordance with some previous studies, other studies suggested that the luminal presservation achieved by the Cypher stent and measured by coronary angiography may be slightly superior to that of the Taxus stent [30-33]. 
In the initial randomized clinical trials, the incidence of DES thrombosis was less than $1 \%(0.4 \%$ at 1 year in the Sirolimus-Eluting Stent [SIRIUS] study [34,35] and $0.6 \%$ at 9 months in the TAXUS IV study [36]. None of the randomized data found any statistically significant difference between the incidence of thrombosis associated with DESs or BMSs. In our study, the incidence of late DES thrombosis versus BMS was high being $(2.7 \%$ versus $4.6 \%$ ) respectively, although the difference was statistically non significant, it is concordant with two meta-analyses that suggested that drug-eluting stents do not increase the overall incidence of stent thrombosis.

In our study, the DES group had significantly smaller base-line MLD compared to the BMS group especially in the aorto-ostial and non aorto-ostial groups ( $p$ value 0.036 and 0.037 respectively); thus it consisted of lesions more prone to restenosis. Furthermore, the base-line diameter \% stenosis in the two DES groups was significantly higher than that of the BMS ostial groups, lesion rigidity might be a possible explanation for this finding. Histological data from pathologic series [37] and atherectomy specimens [38] showed that ostial lesions are frequently heavily calcified, fibrotic, and sclerotic.

Although, DES implantation has been successful in reducing TLR in ostial lesions with no increase in major in-hospital complications [39], Cosgrave et al. [40] reported that DES implantation in complex lesions includeing ostial lesions has not completely abolished the restenotic response, even though most demonstrated restenosis show more benign pattern and were more amenable to percutaneous treatment.

Based on the limited early studies evaluating restenotic lesions in Sirolimus-eluting stent (SES) and $\mathrm{Pa}-$ clitaxel-eluting stent (PES), there was a general concept that when restenosis occurs it is likely to be focal. These initial data were mainly derived from the early experiences with DES [41,42] or from selected cohorts [43]. This observation combined with the knowledge that focal restenosis in bare metal stents (BMS) carries a more benign prognosis than non-focal restenosis [44], have led to further evaluation of the pattern of restenosis in the DES era. In our study, the total incidence of focal instent restenosis was higher than that of non-focal type of restenosis in the DES treated patients how have documented instent restenosis during follow up angiograms, being 15 patients versus 5 patients respectively. Moreover, the incidence of focal pattern of restenosis in the Sirolimus eluting stent (Cypher) was lower than that of the Paclitaxel eluting stent (Taxus), but the result was not statistically significant. Our observation about the pattern of restenosis after DES agrees with the finding of previous study done by Colombo et al. [45], which reported that focal restenosis is the most common pattern of restenosis in DES.
In conclusion, although effective treatment of ostial coronary lesions remains technically challenging, drug eluting stent implantation in coronary ostial lesions is considered safe and feasible. It is associated with high procedural success rate, low immediate and in-hospital complication rate, infrequent late adverse events and favourable long-term clinical and angiographic outcomes compared with bare metal stents implantation. Advanced age, previous myocardial infarction and acute coronary syndromes at presentation were all found to be independent positive predictors for clinical events after drug eluting stent implantation in ostial lesions.

\section{STUDY LIMITATION}

1) The fact was that it was prospective and retrospective, single centre study and lacked the clear advantages of the randomized trial. 2) The study population was a heterogeneous group in terms of clinical characteristics and the nature of the treated lesions and the choice of equipment used varied at the discretion of the operator. 3) Relatively small study population in each study subgroup. 4) Two types of drug eluting stents were used in the study, where sirolimus eluting stents (Cypher) were more commonly used. 5) No debulking devices, such as directional coronary atherectomy (DCA) or rotational coronary atherectomy (RCA) were used in this study; Such devices could reduce the plaque burden before stent implantation, increase the luminal diameter, reduce the angiographic restenosis rate and improve the clinical outcomes especially in aorto-ostial lesions. 6) Intravascular ultrasound (IVUS) was not routinely used in this study; The use of IVUS may affect therapeutic strategy; provide an optimal selection of stent size and other procedures.

\section{REFERENCES}

[1] Barragan, P., Rieu, R., Garitey, V., et al. (2000) Elastic recoil of coronary stents: A comparative analysis. Catheterization and Cardiovascular Interventions, 50, 112-119. doi:10.1002/(SICI)1522-726X(200005)50:1<112::AID-C CD25>3.0.CO;2-X

[2] Escaned, J., Hernandez, R., Baquero, M., et al. (1999) Double stenting as a treatment for stent collapse in the left main coronary artery. Journal of Invasive Cardiology, 11, 305-308.

[3] Lederman, R.J. and Moscucci, M. (1998) Superimposed stents in the management of acute recoil after PalmazSchatz stenting. Catheterization and Cardiovascular Diagnosis, 44, 407-410. doi:10.1002/(SICI)1097-0304(199808)44:4<407::AID-C $\underline{\mathrm{CD} 8>3.0 . \mathrm{CO} ; 2-8}$

[4] Kurbaan, A.S. and Kelly, P.A. (1997) Sigwart: Using cutting balloon angioplasty and stenting for aorto-ostial lesions. Heart, 77, 350-352.

[5] Eigler, N., Weinstock, B., Douglas, J.S., Goldenberg, T., 
Hartzler, G., Holmes, D., et al. (1993) Excimer laser coronary angioplasty of aorto-ostial stenosis: Results of excimer laser coronary angioplasty (ELCA) registry in the first 200 patients. Circulation, 88, 2049-2057. doi:10.1161/01.CIR.88.5.2049

[6] Jain, S.P., Liu, M.W., Dean, L.S., Babu, R., Goods, C.M., Yaday, J.S., Al-Shaibi, K.F., Mathur, A., Lyer, S.S., Parks, J.M., Baxley, W.A. and Roubin, G.S. (1997) Comparison of balloon angioplasty versus debulking devices versus stenting in right coronary ostial lesions. The American Journal of Cardiology, 79, 1334-1338. doi:10.1016/S0002-9149(97)00135-5

[7] Koller, P.T., Freed, M., Grines, C.L. and O’Neill, W.O. (1994) Success, complications and restenosis following rotational and transluminal extraction atherectomy of ostial stenosis. Catheterization and Cardiovascular Diagnosis, 31, 255-260. doi:10.1002/ccd.1810310402

[8] Fischman, D.L., Leon, M.B., Baim, D.S., et al. (1994) A randomized comparison of coronary-stent placement and balloon angioplasty in the treatment of coronary artery disease. Stent restenosis study investigators. The New England Journal of Medicine, 331, 496-501. doi:10.1056/NEJM199408253310802

[9] Serruys, P.W., de Jaegere, P., Kiemeneij, F., et al. (1994) A comparison of balloon-expandable-stent implantation with balloon angioplasty in patients with coronary artery disease. Benestent study group. The New England Journal of Medicine, 331, 489-495.

doi:10.1056/NEJM199408253310801

[10] Silvestri, M., Barragan, P., Sainsous, J., et al. (2000) Unprotected left main coronary artery stenting: Immediate and medium-term outcomes of 140 elective procedures. Journal of the American College of Cardiology, 35, 1543-1550. doi:10.1016/S0735-1097(00)00588-X

[11] Gambhir, D.S., Batra, R., Singh, S., et al. (1998) Comparison of in-hospital and follow-up results of directional atherectomy and stenting for ostial lesions of the left anterior descending coronary artery. Indian Heart Journal, 50, 35-39.

[12] Gregory, C.R., Huie, P., Billinghan, M.E. and Morris, R.E. (1993) Rapamycin inhibits arterial intimal thickening caused by both alloimmune and mechanical injury. Its effect on cellular, growth factor, and cytokine response in injured vessels. Transplantation, 55, 1409-1418. doi:10.1097/00007890-199306000-00037

[13] Suzuki, T., Kopia, G., Hayashi, S.-I., Bailey, L.R., Lianos, G., Wilensky, R., Klugherz, B.D., Papanderou, G., Narayan, P., Leon, M.B., et al. (2001) Stent-based delivery of Sirolimus reduce neointimal formation in a porcine coronary model. Circulation, 104, 1188-1193. doi:10.1161/hc3601.093987

[14] Romero, M., de Lezo, J.S., Medina, A., et al. (2004) Randomized drug-eluting stent comparison: Rapamycin versus Paclitaxel in coronary lesions prone to restenosis. Circulation, 110, 111-564.

[15] Lemos, P.A., Hoye, A., Goedhart, D., et al. (2004) Clini$\mathrm{cal}$, angiographic, and procedural predictors of angiographic restenosis after Sirolimus-eluting stent implantation in complex patients: An evaluation from the Rapa- mycin-eluting stent evaluated at rotterdam cardiology hospital (RESEARCH) study. Circulation, 109, 13661370. doi:10.1161/01.CIR.0000121358.26097.06

[16] Ruiz-Nodar, J.M., Frutos, A., Carrillo, P., et al. (2004) Use of Sirolimus-eluting stents in complex lesions: Clinical and angiographic follow-up. Revista Española de Cardiología, 57, 123-129. doi:10.1157/13057262

[17] Moses, J.W., Leon, M.B., Popma, J.J., et al. (2003) Sirolimus-eluting stents versus standard stents in patients with stenosis in a native coronary artery. The New England Journal of Medicine, 349, 1315-1323. doi:10.1056/NEJMoa035071

[18] Grube, E., Silber, S., Hauptmann, K.E., et al. (2003) TAXUS I: Six- and twelve-month results from a randomized, double-blind trial on a slow-release Paclitaxel-eluting stent for de novo coronary lesions. Circulation, 107, 38-42. doi:10.1161/01.CIR.0000047700.58683.A1

[19] Stone, G.W., Ellis, S.G., Cox, D.A., et al. (2004) A polymer-based, Paclitaxel-eluting stent in patients with coronary artery disease. The New England Journal of Medicine, 350, 221-231.

[20] Eigler, N.L., Stock, W.B., Douglas Jr., J.S., Goldenberg, T., Hartzler, G., Holmes, D., Leon, M., Margolis, J., Nobuyoshi, M., O’Neill, W., Rothbaum, D., Roubin, G., Untereker, W., Cowley, M., Forrester, J. and Litvack, F. (1993) Excimer laser coronary angioplasty of aorto-ostial stenoses. Circulation, 88, 2049-2057. doi:10.1161/01.CIR.88.5.2049

[21] Kerwin, P.M., McKeever, L.S., Marek, J.C., Hartmann, J.R. and Enger, E.L. (1993) Directional atherectomy of aorta ostial stenoses. Catheterization and Cardiovascular Diagnosis, 1, 17-25.

[22] Popma, J.J., Brogan III, W.C., Pichard, A.D., Satler, L.F., Kent, K.M., Mintz, G.S. and Leon, M.B. (1993) Rotational coronary atherectomy of ostial stenoses. The American Journal of Cardiology, 71, pp. 436-438. doi:10.1016/0002-9149(93)90448-L

[23] LawsonA, C.S., Cooper, I.C. and Webb-Peploe, M.W. (1993) Initial experience with excimer laser angioplasty for coronary ostial stenoses. British Heart Journal; 69, 225-259.

[24] Park, S.J., Kim, Y.H., Lee, B.K., Lee, S.W., Lee, C.W., Hong, M.K., Kim, J.J., Mintz, G.S. and Park, S.W. (2005) Sirolimus-eluting stent implantation for unprotected left main coronary artery stenosis. Comparison with bare metal stent implantation. Journal of the American College of Cardiology, 45, 351-356. doi:10.1016/j.jacc.2004.10.039

[25] Tsagalou, E., Stancovic, G., Iakovou, I., Melzi, G., Cosgrave, J., Ge, L., Michev, I., Chieffo, A., Airoldi, F., Carlino, M., Montorfano, M. and Colombo, A. (2006) Early outcome of treatment of ostial de novo left anterior descending coronary artery lesions with drug-eluting stents. The American Journal of Cardiology, 97, 187-191. doi:10.1016/j.amjcard.2005.07.131

[26] Moses, J.W., Leon, M.B., Popma, J.J., et al. (2003) Sirolimus-eluting stents versus standard stents in patients with stenosis in a native coronary artery. The New England Journal of Medicine, 349, 1315-1323. 
doi:10.1056/NEJMoa035071

[27] Morice, M.C., Serruys, P.W., Sousa, J.E., et al. (2002) A randomized comparison of a sirolimus-eluting stent with a standard stent for coronary revascularization. The New England Journal of Medicine, 346, 1773-1780. doi:10.1056/NEJMoa012843

[28] Park, D.W., Hong, M.K., Park, S.W. and Park, S.J. (2007) Results and predictors of angiographic restenosis and long-term adverse cardiac events after drug-eluting stent implantation for aorto-ostial coronary artery disease. The American Journal of Cardiology, 99, 760-765. doi:10.1016/j.amjcard.2006.10.028

[29] Ong, A.T., McFadden, E.P., Regar, E., de Jaegere, P.P., van Domburg, R.T. and Serruys, P.W. (2005) Late angiographic stent thrombosis (LAST) events with drug-eluting stents. Journal of the American College of Cardiology, 45, 2088-2092. doi:10.1016/j.jacc.2005.02.086

[30] Cosgrave, J., Agostoni, P., Iakovou, I., Chieffo, A., Giuseppe, G., Biondi-Zoccai, L., Colombo, A., et al. (2005) Clinical outcome following aleatory implantation of paclitaxel-eluting or sirolimus-eluting stents in complex coronary lesions. The American Journal of Cardiology, 96, 1663-1668. doi:10.1016/j.amjcard.2005.07.082

[31] Morice, M.C., Colombo, A., Meier, B., Serruys, P., Tamburino, C., Guagliumi, G., Sousa, E. and Stoll, H.P. (2006) Sirolimus- vs paclitaxeleluting stents in de novo coronary artery lesions: The REALITY trial: A randomized controlled trial. JAMA, 295, 895-904. doi:10.1001/jama.295.8.895

[32] Kastrati, A., Mehilli, J., von Beckerath, N., Alban Dibra, A., Hausleiter, J., Pache, J., Schühlen, H., Schmitt, C., Dirschinger, J. and Schömig, A. (2005) Sirolimus-eluting stent or paclitaxel-eluting stent vs balloon angioplasty for prevention of recurrences in patients with coronary instent restenosis: A randomized controlled trial. JAMA, 293, 165-171. doi:10.1001/jama.293.2.165

[33] Windecker, S., Remondino, A., Eberli, F., Jüni, P., Räber, L., Wenaweser, P., Togni, M., Billinger, M., Tüller, D., Seiler, C., Roffi, M., Corti, R., Sütsch, G., Maier, W., Lüscher, T., Hess, O.M., Egger, M. and Meier, B. (2005) Sirolimus-eluting and paclitaxel-eluting stents for coronary revascularization. The New England Journal of Medicine, 353, 653-662. doi:10.1056/NEJMoa051175

[34] Moussa, I., Leon, M.B., Baim, D.S., O’Neill, W.W., Popma, J.J., Buchbinder, M., Midwall, J., Simonton, C.A., Keim, E., Wang, P., et al. (2004) Impact of sirolimuseluting stents on outcome in diabetic patients. A SIRIUS (SIRolImUS-coated $\mathrm{Bx}$ Velocity balloon-expandable stent in the treatment of patients with de novo coronary artery lesions) Substudy. Circulation, 109, 2273-2278. doi:10.1161/01.CIR.0000129767.45513.71

[35] Guagliumi, G., Farb, A., Musumeci, G., et al. (2003) Sirolimus-eluting stent implanted in human coronary artery for 16 months: Pathological findings. Circulation, 107, 1340-1341. doi:10.1161/01.CIR.0000062700.42060.6F

[36] Stone, G.W., Ellis, S.G., Cox, D.A., et al. (2004) A polymer-based, paclitaxel-eluting stent in patients with coronary artery disease. The New England Journal of Medicine, 350, 221-231. doi:10.1056/NEJMoa032441

[37] Stewart, J.T., Ward, D.E., Davies, M.J. and Pepper, J.R. (1987) Isolated coronary ostial stenosis: Observations on the pathology. European Heart Journal, 8, 917-920.

[38] Popma, J.J., Dick, R.J., Haudenschild, C.C., Topol, E.J. and Ellis, S.G. (1991) Atherectomy of right coronary ostial stenoses: Initial and long-term results, technical features and histologic findings. The American Journal of Cardiology, 67, 431-433. doi:10.1016/0002-9149(91)90057-R

[39] Maniyal, V., Gaston, A.R.G., Pedro, A.L., Jiro, A., Angela, H., Patrick, W.S., et al. (2005) Sirolimus-eluting stents for the treatment of atherosclerotic ostial lesions. The Journal of Invasive Cardiology, 17, 10-12.

[40] Cosgrave, J., Agostoni, P., Ge, L., Iakovou, I., Chieffo, A., et al. (2005) Clinical outcome following aleatory implantation of paclitaxel-eluting or sirolimus-eluting stents in complex coronary lesions. The American Journal of Cardiology, 96, 1663-1668. doi:10.1016/j.amjcard.2005.07.082

[41] Colombo, A., Orlic, D., Stankovic, G., Corvaja, N., Spanos, V., Montorfano, M., Liistro, F., Carlino, M., Airoldi, F., Chieffo, A. and Di Mario, C. (2003) Preliminary observations regarding angiographic pattern of restenosis after rapamycineluting stent implantation. Circulation, 107, 2178-2180. doi:10.1161/01.CIR.0000070592.04766.36

[42] Lemos, P.A., Saia, F., Ligthart, J.M.R., Arampatzis, C.A., Sianos, G., Tanabe, K., Hoye, A., Degertekin, M., Daemen, J., McFadden, E., Hofma, S., Smits, P.C., De Feyter, P., Van der Giessen, W.J., Van Domburg, R.T. and Serruys, P.W. (2003) Coronary restenosis after sirolimus-eluting stent implantation: Morphological description and mechanistic analysis from a consecutive series of cases. Circulation, 108, 257-260. doi:10.1161/01.CIR.0000083366.33686.11

[43] Stone, G.W., Ellis, S.G., Cox, D.A., Hermiller, J., O’Shaughnessy, C., Tift Mann, J., Turco, M., Caputo, R., Bergin, P., Greenberg, J., Popma, J.J. and Russell, M.E. (2004) A polymer-based, paclitaxel-eluting stent in patients with coronary artery disease. The New England Journal of Medicine, 350, 221-231. doi:10.1056/NEJMoa032441

[44] Popma, J.J., Leon, M.B., Moses, J.W., Holmes Jr., D.R., Cox, N., Fitzpatrick, M., Douglas, J., Lambert, C., Mooney, M., Yakubov, S. and Kuntz, R.E. (2004) Quantitative assessment of angiographic restenosis after sirolimus-eluting stent implantation in native coronary arteries. Circulation, 110, 3773-3780. doi:10.1161/01.CIR.0000150331.14687.4B

[45] Mehran, R., Dangas, G., Abizaid, A.S., Mintz, G.S., Lansky, A.J., Satler, L.F., Pichard, A.D., Kent, K.M., Stone, G.W. and Leon, M.B. (1999) Angiographic patterns of in-stent restenosis: Classification and implications for long-term outcome. Circulation, 100, 1872-1878. doi:10.1161/01.CIR.100.18.1872 